\section{Validity of the Brazilian version of the Godin-Shephard Leisure-Time Physical Activity Questionnaire}

\author{
Validade da versão brasileira do Godin-Shephard \\ Leisure-Time Physical Activity Questionnaire
}

\author{
Validez de la versión brasileña del Godin-Shephard \\ Leisure-Time Physical Activity Questionnaire
}

Thaís Moreira São João 1 Roberta Cunha Matheus Rodrigues 1 Maria Cecília Bueno Jayme Gallani 2 Cinthya Tamie Passos Miura 1

Gabriela de Barros Leite Domingues 1 Steve Amireault 3

Gaston Godin 2

\footnotetext{
${ }^{1}$ Faculdade de Enfermagem, Universidade Estadual de Campinas, Campinas, Brasil. 2 Faculté des Sciences Infirmières, Université Laval, Québec, Canada. 3 College of Health and Human Sciences, Purdue University, West Lafayette, U.S.A

Correspondence T. M. São João Faculdade de Enfermagem, Universidade Estadual de Campinas.

Rua Tessália Vieira de Camargo 12, Campinas, $S P$ 13083-887, Brasil. tsaojoao@unicamp.br
}

\begin{abstract}
This study provides evidence of construct validity for the Brazilian version of the GodinShephard Leisure-Time Physical Activity Questionnaire (GSLTPAQ), a 1-item instrument used among 236 participants referred for cardiopulmonary exercise testing. The Baecke Habitual Physical Activity Questionnaire (Baecke-HPA) was used to evaluate convergent and divergent validity. The self-reported measure of walking (QCAF) evaluated the convergent validity. Cardiorespiratory fitness assessed convergent validity by the Veterans Specific Activity Questionnaire (VSAQ), peak measured $\left(V_{2 p e a k}\right)$ and maximum predicted ( $\mathrm{VO}_{2 \text { pred }}$ ) oxygen uptake. Partial adjusted correlation coefficients between the GSLTPAQ, Baecke-HPA, QCAF, VO ${ }_{2 \text { pred }}$ and VSAQ provided evidence for convergent validity; while divergent validity was supported by the absence of correlations between the GSLT$P A Q$ and the Occupational Physical Activity domain (Baecke-HPA). The GSLTPAQ presents level 3 of evidence of construct validity and may be useful to assess leisure-time physical activity among patients with cardiovascular disease and healthy individuals.
\end{abstract}

Cardiovascular Diseases; Motor Activity; Validation Studies; Questionnaires; Psychometry

\section{Resumo}

Este estudo fornece evidências de validade de construto da versão brasileira do Godin-Shephard Leisure-Time Physical Activity Questionnaire (GSLTPAQ), instrumento de 1 item usado entre 236 participantes encaminhados ao teste de esforço cardiopulmonar. $O$ Questionário de Atividade Física Habitual de Baecke (AFHBaecke) avaliou a validade convergente e divergente. A medida de autorrelato de caminhada (QCAF) acessou a validade convergente. A aptidão cardiorrespiratória avaliou a validade convergente por meio do Veterans Specific Activity Questionnaire (VSAQ), consumo pico $\left(\mathrm{VO}_{2 p i c o}\right)$ e máximo $\left(\mathrm{VO}_{2 p r e d}\right)$ de oxigênio. Coeficientes de correlação parciais ajustados entre o GSLTPAQ, Baecke-HPA, QCAF, VO ${ }_{2 \text { pred }}$ e VSAQ forneceram evidências de validade convergente; enquanto a validade divergente foi apoiada pela ausência de correlações entre a GSLTPAQ $e$ o domínio Atividade Física Ocupacional (AFHBaecke). O GSLTPAQ apresenta nível 3 de evidência de validade de construto e parece útil para avaliar a atividade física no tempo de lazer entre pacientes com doença cardiovascular $e$ indivíduos saudáveis.

Doenças Cardiovasculares; Atividade Motora; Estudos de Validação; Questionários; Psicometria 


\section{Background}

It is widely recognized that regular participation in physical activity and exercise results in several positive health-related outcomes, from both a preventive and a rehabilitative perspective 1 . physical activity is defined as "any bodily movement produced by skeletal muscles that results in energy expenditure" 2 (p. 126). physical activity can further be categorized in a range of ways and the simplest classification identifies the physical activity that occurs during the different moments of a regular day: sleeping, at work, and at leisure 2 .

Nowadays it is acknowledged that there is less physical activity in the working environment in industrialized countries, due to an increase in technology and the automation of tasks, leading to people taking up more sedentary jobs 3 . For this reason, occupational physical activity has decreased over time ${ }^{4}$ and leisure-time physical activity has received widespread attention, making it a more representative measure of physical activity practiced by the economically active population 5 . Moreover, sedentary individuals in their leisuretime also present the lowest levels of overall physical activity in their daily life, suggesting that leisure-time physical activity is one of the most important dimensions of overall physical activity 6 . Thus, an accurate assessment of the leisure-time physical activity dimension of physical activity is relevant.

In this context, the Godin-Shephard LeisureTime Physical Activity Questionnaire (GSLTPAQ) is considered a valid and reliable instrument that is used worldwide as a measure of leisure-time physical activity. Among the questionnaires for the measurement of physical activity, this specific one was created in Canada in 1985 to fill a perceived gap in the literature, given the absence of a concise and simple instrument that is valid, reliable and capable of measuring physical activity in leisure time. The instrument's questions were developed after careful evaluation of items used in other questionnaires that had demonstrated, using univariate analyses, that they could successfully discriminate between very active individuals and those who were sedentary 7 . This unidimensional 1-item questionnaire was developed and validated within a study with 306 Canadian healthy adults (163 men and 143 women) aged from 18 to 65 years 7 . Values of body fat $(r=0.13$; $\mathrm{p}<0.01$; Pearson correlation coefficient) and predicted maximal oxygen consumption $(\mathrm{r}=0.24 ; \mathrm{p}<$ 0.001; Pearson correlation coefficient), expressed in percentiles appropriate for age and sex were used as criteria for the validation of the questionnaire. Since its validation, the questionnaire has been used among different populations in several countries 8,9,10,11,12,13,14,15 and evaluated by different studies 16,17,18 and reviews 19,20.

The GSLTPAQ score is expressed in units and can be computed in two steps. First, weekly frequencies of strenuous, moderate, and mild activities are multiplied by nine, five, and three, respectively; these three latter values correspond to MET value categories for the activities listed. The total weekly leisure activity score is then computed in arbitrary units by summing the products of the separate components, as shown in the following formula 7 :

Weekly leisure-time activity score $=(9 \mathrm{x}$ Strenuous $)+(5$ x Moderate $)+(3 \times$ Mild $)$

Recently 18 , the author of the GSLTPAQ reviewing the instrument, proposed a categorization of its total score as "active", "moderately active" and "insufficiently active", in regard to the well-documented "dose response" relationship between physical activity and health.

Although the GSLTPAQ has demonstrated its relevance to science and to the study of physical activity $17,19,20$, there was no version available to the Brazilian scientific community. Thus, a previous study was conducted to proceed to the crosscultural adaptation to Brazil of GSLTPAQ 21. The Brazilian GSLTPAQ demonstrated evidence of content validity and reliability regarding stability (ICC = 0.84) 21 . However, reliability is essential, but not sufficient for validity. Therefore, this study aims to present the validation process of the Brazilian version of GSLTPAQ regarding convergent and divergent construct validity.

\section{Methods}

\section{Settings and sample}

This study was carried out in Southeastern Brazil. Data were gathered over a 5-month period in 2011, consecutively until the end of the established period for data collection. Participants were then allocated into three groups: healthy volunteers $(n=100)$, hypertensive $(n=100)$ and coronary heart disease (CHD) outpatients $(\mathrm{n}=36)$.

Participants were recruited on the day of their regular appointment for the cardiopulmonary exercise test, conducted by a cardiologist and accompanied by a nurse or a physiotherapist to carry out the gas analysis. Participants using drug altering heart rate were not included in this sample. The investigation conforms to the principles outlined in the Declaration of Helsinki. 
Sociodemographic data were obtained through interview-administered instruments that were tested beforehand 22. Clinical data were gathered through analysis of medical records and interview. Clinical associated conditions were assessed. Direct measures were made to obtain anthropometric data.

\section{Questionnaires}

All the questionnaires were administered by means of interview, in order to respect different levels of schooling among participants.

\section{- Godin-Shephard Leisure-Time Physical Activity Questionnaire}

The 1-item questionnaire aimed at evaluating the weekly frequency and intensity of the leisuretime physical activity session of "at least 15 minutes" was used. A suggestion was made to only consider the frequency of moderate and strenuous activity for computing the total score of the GSLTPAQ, since most of the activities listed as "mild" in the original instrument did not provide substantial health benefits, except for light walking and golf 18 . However, given that walking plays an important role in the range of the Brazilian physical activity 23 , it was decided to keep the total score of GSLTPAQ. The results are therefore presented according to both scores - with and without mild activities.

In the present study, the GSLTPAQ score was presented as a dichotomized variable, because $60.6 \%$ of the participants reported no participation in leisure-time physical activity when including mild activities, but $83.9 \%$ of them were considered inactive when excluding mild activities based on the GSLTPAQ score. This fact does not affect the quality of the data, since the continuous GSLTPAQ score presented the same performance. In order to respect data distribution, the dichotomization was carried out by attributing a score of zero (0) to participants who were classified as "moderately active" and "insufficiently active". On the other hand, those who were categorized as "active" received a score of one (1). Although the questionnaire was previously constructed to be self-administered, in our study it was administered by means of interview, with the agreement of the author of the original instrument.

\section{- Self-report measure of walking behavior}

This measure was derived from the Psychosocial Determinants of Physical Activity among Coronary Heart Disease Patients Questionnaire 22. In this question, respondents were asked "In the last month, how many times have you walked at least 30 minutes?" This was assessed by means of a 4-point scale ranging from less than once a week (1), to up to 3 or more times per week (4). The questionnaire was originally developed in interview form and its content was validated among coronary heart disease outpatients in a previous study 22 .

\section{- Habitual physical activity - the Baecke Questionnaire}

The Brazilian version of the Baecke Questionnaire of Habitual Physical Activity (Baecke-HPA) was used 24. The Baecke-HPA is easy to understand and apply, and ensures qualitative and quantitative indices through 16 questions encompassing three dimensions of physical activity in the past 12 months: (1) occupational physical activity (8 questions); (2) physical exercises in leisure (4 questions); and (3) leisure and locomotion activities (4 questions). The items are scored on a five-point Likert scale, ranging from never to always, generating scores from 1 to 5 , with higher scores indicating higher levels of physical activity. The total score (HPA-score) is a summation of the three dimensional scores and the range varies from 3 (inactive) to 15 (very active). This questionnaire has been used among healthy 24,25 and non-healthy 26 populations and is considered a valid and reliable tool for measuring physical activity. As for the validity, the questionnaire has been tested with evidences of valid measures of physical activity 24,26. Although in the original study this questionnaire was self-administered, in our study it was administered by means of interview.

\section{- Veterans Specific Activity Questionnaire}

The Brazilian version of the Veterans Specific Activity Questionnaire (VSAQ) was applied prior to exercise testing 27 . The VSAQ makes it possible to determine different intensities of daily activities that are limited by cardiovascular disease symptoms. It consists of a list of activities presented in progressive order according to METs, ranging from 1 to 13 . The MET values associated with each activity were derived from the Brazilian version of the Compendium of Physical Activities. The VSAQ score was age-adjusted by using a nomogram according to the equation: METs $=4.7$ 
+ 0.97 (VSAQ) - 0.06 (age), as recommended 28 . In the present study, the original unit of the questionnaire (METs) was converted to $\mathrm{ml} . \mathrm{kg}^{-1} . \mathrm{min}^{-1}$, by multiplying the VSAQ score by 3.5 , in order to standardize data, according to the other measures of cardiorespiratory fitness used in the study, that consider the same unit. The VSAQ has demonstrated acceptable levels of reliability (kappa = $0.86 ; \mathrm{p}<0.001)$ and was strongly correlated with measured-peak $\mathrm{VO}_{2}(\mathrm{r}=0.63 ; \mathrm{p}<0.001) 27$. Although in the original study this questionnaire was self-administered, in our study it was administered by interview, as in the validation of the Brazilian version 27.

\section{- Measures of cardiorespiratory fitness}

Three methods were assessed: the Brazilian version of theVSAQ, the maximum direct oxygen uptake and the maximum predicted oxygen uptake. Since physical activity consists of a behavioral attribute, which comprises the energy expenditure from volitional and non-volitional activities, it most commonly relied on self-reports. But while questionnaires can be useful tools to report outcomes, they may lack the validity necessary to predict health results in individuals. Therefore, maximum oxygen uptake predicted $\left(\mathrm{VO}_{2 \text { pred }}\right)$ is considered adequate as an indirect criterion for questions regarding higher intensities. Highest correlations have been demonstrated in questions about vigorous, rather than light and moderate activities 6 .

\section{- Cardiopulmonary exercise testing in treadmill with oxygen uptake}

Exercise testing with oxygen uptake analysis was performed on a treadmill using ramp protocol, as recommended 29 . The exercise was terminated for generalized fatigue, symptom or sign limits, or electrocardiographic changes for all participants 30 .

Oxygen uptake was determined and averaged every 10 seconds using the MedGraphics VO2000 portable metabolic measurement system and the software Aerograph (Medical Graphics Corp., St. Paul, U.S.A.). Gas exchange was obtained with the individual wearing a nose clip and a facial mask, breathing room air through a one-way directional valve system. Peak oxygen uptake $\left(\mathrm{VO}_{2 \text { peak }}\right)$ was defined as the maximum attained oxygen consumption at the end of exercise testing. Calibration of the system was performed according to the recommendations of the manufacturer.

In addition to the direct measure of oxygen consumption, the maximum oxygen uptake predicted $\left(\mathrm{VO}_{2 \text { pred }}\right)$ was estimated by means of the software used during the test, which is based on the equation proposed by the American College of Sports Medicine - ACSM (where $\mathrm{VO}_{2 \max }=($ Heart Rate $\mathrm{x}$ Stroke Volume) $\mathrm{x}$ (arteriovenous oxygen difference)) and recommended by the American Heart Association (AHA), considering it as the highest rate at which oxygen can be taken up and used by the body during severe exercise 31 .

The $\mathrm{VO}_{2 \text { pred }}$ outcome was selected once it is already known that patients with cardiovascular diseases are not able to reach VO2max, which corresponds to the real maximum oxygen consumption during exercise. Participants referred to the test were advised by their doctors to stop the use of beta-blockers before the test. Participants who did not follow their doctor's recommendation were re-scheduled for another day or not included.

\section{Measurement properties}

Validity is indicated as the degree of authenticity and refers to how the test measures what it is intended to measure and can also be defined as the extent to which an instrument measures the true exposure of interest. There are three main types of validity: content, construct and criterion 32 .

In the present study, construct validity was assessed. It is one of the most important characteristics of a measuring instrument, since it corresponds to the assessment of the degree to which an instrument measures the construct that it was designated to measure, and involves hypotheses testing. It can be assessed by correlational evidence (convergent validity), the absence of correlational evidence (divergent validity), discriminant evidence (discriminant validity) and factor analysis 33 . Convergent validity is achieved when correlational evidence between two or more measures that measure the same construct is observed. Divergent validity is obtained when there is a lack of correlation between variables measuring theoretically different constructs and that, therefore, should not present correlational evidence 32,33 .

\section{Statistics}

Convergent validity of the GSLTPAQ was tested with self-reported measure of behavior, Baecke scores (physical exercise in leisure and leisure and locomotion activities), VSAQ score and measures of oxygen uptake; and divergent validity was tested using the Occupational Physical Activity (OPA) Domain (Baecke-HPA). All the correlation analyses were conducted using adjusted 
partial coefficients with $95 \%$ confidence interval (95\%CI) controlling for sex, age, education, body mass index (BMI) and disease groups (CHD or hypertension). The use of adjusted partial correlations was decided considering that once the size measure effect (i.e., the correlation coefficient) is adjusted for other variables, the goal is to prevent detecting spurious correlations. Therefore, correlation coefficients of a magnitude between 0.30 and 0.50 were considered as acceptable values 34 . The presence of univariate or multivariate outliers was verified and none were identified.

With the purpose of respecting the analyses of data distribution and although the continuous GSLTPAQ score presented the same performance, the analyses of dichotomized GSLTPAQ scores were presented. The score was then dichotomized into two categories: some activity (score $>0$ ) and inactivity (score $=0$ ) in individuals.

The Statistical Analysis System for Windows program, version 9.2 (SAS Inst., Cary, U.S.A.) was used for all statistical analyses.

\section{Hypotheses}

\section{- Convergent construct validity}

Significant positive correlation was expected between the GSLTPAQ score:

1) And the domain Physical Exercise in Leisure (PEL) of the Baecke-HPA. This domain investigates the practice of regular physical activity exclusively during leisure-time, considering different levels of intensity, according to energy expenditure (mild, moderate or vigorous) and also provides duration and frequency of leisure-time physical activity (hours per week and months per year) for each activity reported;

2) And the domain Leisure and Locomotion Activities (LLA) of the Baecke-HPA. This domain refers to such activities of leisure as watching television, walking, cycling and minutes spent daily with activities of locomotion (walking or use a bicycle to go to work, school or shopping);

3) Including mild activities and the self-reported measure of walking behavior, since walking is considered a mild physical activity;

4) Including mild activities and the measures of cardiorespiratory fitness;

5) Excluding mild activities and the measures of cardiorespiratory fitness.

\section{- Divergent construct validity}

No correlation was expected between the GSLTPAQ score and the domain OPA of the
Brazilian version of the Baecke-HPA, since this domain contains specific questions regarding work activities.

\section{Ethical aspects}

Participants were invited to engage in the research and their agreement was formalized by signing a consent term. Ethical approval was granted from the Faculty of Medical Sciences ethics committee of the Campinas State University (document n. 1,062/2009). All participants provided informed voluntary consent.

\section{Results}

\section{Sociodemographic and clinical} characterization

The sample was composed mostly of females, with the exception of the CHD group. Ages ranged from 19 to 77 years, with a mean of 52.8 (11.1) years. Education ranged from 0 to 16 years, with a low mean among the total sample and groups. Family monthly income ranged from US\$ 109.30 to US\$ $4,371.60$ and mean income was US\$ 911.70. The majority of the sample was white, living with a companion and professionally active, except for the CHD group, and was composed mostly of housewives. The number of symptoms ranged from 0 to 7 , with similar means for the total sample, hypertensive individuals and the CHD group (Table 1). Symptoms and associated clinical conditions were not evaluated among healthy volunteers. Angina was the most frequently reported symptom over the last month, followed by fatigue and palpitation, in both groups. Edema was referred to by $50 \%$ of people from the CHD group and $46 \%$ of hypertensive patients. Fainting was a complaint of $49 \%$ of hypertensive and $36.1 \%$ of CHD patients; and dyspnea was perceived in $44 \%$ of hypertensive and in $36.1 \%$ of CHD patients (Table 1 ).

The number of associated clinical conditions ranged from 0 to 5 . Hypertension was present in CHD patients as a major condition $(63.9 \%)$; followed by dyslipidemia ( $66.7 \%$ for CHD, $32 \%$ for hypertensive individuals); and diabetes (50\% for CHD, 27\% for hypertensive individuals). Among the CHD patients, $67.7 \%$ were diagnosed with myocardial infarction and $33.3 \%$ with angina. The analysis of the BMI revealed predominance of obese and overweight participants, with BMI ranging from 16.9 to $52.6 \mathrm{~kg} / \mathrm{m}^{2}$, with a higher mean for hypertensive patients and similar means for healthy volunteers and CHD patients (Table 1). 
Table 1

Sociodemographic and clinical characterization of the total sample $(N=236)$ and groups: hypertensive patients $(n=100)$, patients with coronary heart disease $(\mathrm{CHD}, \mathrm{n}=36)$ and healthy volunteers $(\mathrm{n}=100)$. Campinas, São Paulo State, Brazil, 2011.

\begin{tabular}{|c|c|c|c|c|c|c|c|c|c|c|c|c|}
\hline \multirow[t]{2}{*}{ Variables } & \multicolumn{3}{|c|}{ Total sample $(\mathrm{N}=236)$} & \multicolumn{3}{|c|}{ Healthy $(n=100)$} & \multicolumn{3}{|c|}{ Hypertensive $(n=100)$} & \multicolumn{3}{|c|}{$\mathrm{CHD}(\mathrm{n}=36)$} \\
\hline & n (\%) & $\begin{array}{l}\text { Mean } \\
\text { (SD) }\end{array}$ & $\begin{array}{c}\text { Median } \\
\text { (IQR) }\end{array}$ & n (\%) & $\begin{array}{c}\text { Mean } \\
\text { (SD) }\end{array}$ & $\begin{array}{c}\text { Median } \\
\text { (IQR) }\end{array}$ & n (\%) & $\begin{array}{c}\text { Mean } \\
(\mathrm{SD})\end{array}$ & $\begin{array}{c}\text { Median } \\
\text { (IQR) }\end{array}$ & n (\%) & $\begin{array}{c}\text { Mean } \\
\text { (SD) }\end{array}$ & $\begin{array}{c}\text { Median } \\
\text { (IQR) }\end{array}$ \\
\hline \multicolumn{13}{|l|}{ Sociodemographic } \\
\hline Age (years) & & $\begin{array}{c}52.8 \\
(11.1)\end{array}$ & $\begin{array}{l}53.0 \\
(14.7)\end{array}$ & & $\begin{array}{c}49.6 \\
(11.5)\end{array}$ & $\begin{array}{c}51.0 \\
(14.7)\end{array}$ & & $\begin{array}{l}54.3 \\
(10.7)\end{array}$ & $\begin{array}{l}54.0 \\
(14.7)\end{array}$ & & $\begin{array}{l}57.3 \\
(8.7)\end{array}$ & $\begin{array}{l}56.5 \\
(11.0)\end{array}$ \\
\hline Education (years) & & $\begin{array}{l}5.7 \\
(3.2)\end{array}$ & $\begin{array}{l}5.0 \\
(4.0)\end{array}$ & & $\begin{array}{l}6.3 \\
(3.3)\end{array}$ & $\begin{array}{c}6.0 \\
(4.0)\end{array}$ & & $\begin{array}{l}5.0 \\
(3.0)\end{array}$ & $\begin{array}{c}4.0 \\
(3.0)\end{array}$ & & $\begin{array}{l}5.8 \\
(3.4)\end{array}$ & $\begin{array}{c}4.0 \\
(4.0)\end{array}$ \\
\hline Family income (US\$) & & $\begin{array}{c}911.7 \\
(620.7)\end{array}$ & $\begin{array}{c}765.0 \\
(588.2)\end{array}$ & & $\begin{array}{l}1,039.2 \\
(730.1)\end{array}$ & $\begin{array}{c}819.7 \\
(726.5)\end{array}$ & & $\begin{array}{c}787.2 \\
(410.9)\end{array}$ & $\begin{array}{c}735.0 \\
(470.6)\end{array}$ & & $\begin{array}{c}903.3 \\
(714.7)\end{array}$ & $\begin{array}{c}683.1 \\
(488.2)\end{array}$ \\
\hline Sex-Female & $\begin{array}{c}138 \\
(58.5)\end{array}$ & & & $\begin{array}{c}52 \\
(52.0)\end{array}$ & & & $\begin{array}{c}73 \\
(73.0)\end{array}$ & & & $\begin{array}{c}13 \\
(36.1)\end{array}$ & & \\
\hline Color - White & $\begin{array}{c}194 \\
(82.2)\end{array}$ & & & $\begin{array}{c}85 \\
(85.0)\end{array}$ & & & $\begin{array}{c}79 \\
(79.0)\end{array}$ & & & $\begin{array}{c}30 \\
(83.3)\end{array}$ & & \\
\hline $\begin{array}{l}\text { Marital status - with } \\
\text { companion }\end{array}$ & $\begin{array}{c}172 \\
(72.8)\end{array}$ & & & $\begin{array}{c}70 \\
(70.0)\end{array}$ & & & $\begin{array}{c}72 \\
(72.0)\end{array}$ & & & $30(83.3)$ & & \\
\hline Professional status & & & & & & & & & & & & \\
\hline Active & $\begin{array}{c}122 \\
(51.7)\end{array}$ & & & $\begin{array}{c}59 \\
(59.0)\end{array}$ & & & $\begin{array}{c}49 \\
(49.0)\end{array}$ & & & $\begin{array}{c}14 \\
(38.9)\end{array}$ & & \\
\hline Non-active/Housewife & $\begin{array}{c}114 \\
(48.3)\end{array}$ & & & $\begin{array}{c}41 \\
(41.0)\end{array}$ & & & $\begin{array}{c}51 \\
(51.0)\end{array}$ & & & $\begin{array}{c}22 \\
(61.1)\end{array}$ & & \\
\hline Clinical & & & & & & & & & & & & \\
\hline Symptoms & & $3.7(2.2)$ & $\begin{array}{l}4.0 \\
(4.0)\end{array}$ & & - & - & & $\begin{array}{c}3.7 \\
(2.2)\end{array}$ & $\begin{array}{l}4.0 \\
(4.0)\end{array}$ & & $\begin{array}{l}3.6 \\
(2.2)\end{array}$ & $\begin{array}{l}3.0 \\
(4.0)\end{array}$ \\
\hline $\begin{array}{l}\text { Associated clinical } \\
\text { conditions }\end{array}$ & & $2.2(1.0)$ & $\begin{array}{l}2.0 \\
(2.0)\end{array}$ & & - & - & & $\begin{array}{c}2.1 \\
(1.0)\end{array}$ & $\begin{array}{l}2.0 \\
(2.0)\end{array}$ & & $\begin{array}{c}2.6 \\
(1.1)\end{array}$ & $\begin{array}{c}3.0 \\
(1.0)\end{array}$ \\
\hline Body mass index & & $29.6(5.6)$ & $\begin{array}{l}29.1 \\
(6.8)\end{array}$ & & $\begin{array}{l}28.3 \\
(5.0)\end{array}$ & $\begin{array}{l}28.2 \\
(6.9)\end{array}$ & & $\begin{array}{l}31.2 \\
(6.0)\end{array}$ & $\begin{array}{l}30.2 \\
(8.3)\end{array}$ & & $\begin{array}{l}28.7 \\
(4.9)\end{array}$ & $\begin{array}{l}27.7 \\
(7.5)\end{array}$ \\
\hline
\end{tabular}

IQR: interquartile range; SD: standard deviation.

\section{Descriptive analysis of physical activity and cardiorespiratory fitness measures}

Regarding the GSLTPAQ score assessment [in order to respect data distribution, the presented analyses refer to the dichotomized GSLTPAQ score (some activity: score $>0$; inactivity: score = $0)$. The continuous GSLTPAQ score presented the same performance that the dichotomized one], the majority of participants reported low scores of leisure-time physical activity - 189 participants were considered insufficiently active according to the GSLTPAQ scores. Considering the GSLTPAQ score with mild activities, 143 people were inactive, with a score of 0 (zero), which represents most of the total sample $(60.6 \%)$. When observing the GSLTPAQ score excluding mild activities, 198 individuals presented a score of 0 (zero), which represents an even larger share of the sample (83.9\%). Concerning the other measures of physical activity, the mean scores of Baecke-HPA and behavior are lower than half of the maximum possible score - the maximum for the Baecke questionnaire is 15 and the observed mean was 7.2, and the maximum score for behavior is 4 , with a mean of 1.7 . The measures of cardiorespiratory fitness also exhibited low levels. The VSAQ presented a mean of 22.0 (9.8) $\mathrm{ml} . \mathrm{kg}^{-1} \cdot \mathrm{min}^{-1}$, the $\mathrm{VO}_{2 \text { peak }}$ mean was 19.7 (5.7) $\mathrm{ml} . \mathrm{kg}^{-1} \cdot \mathrm{min}^{-1}$ and the $\mathrm{VO}_{2 \text { pred }}$ mean was 29.1 (11.3) $\mathrm{ml}^{.} \mathrm{kg}^{-1}$. $\mathrm{min}^{-1}$. Among this sample, five patients of the 236 did not present gas analysis due to technical difficulties during data collection (Table 2). 
Descriptive analyses of physical activity and cardiorespiratory fitness of the total sample ( $N=231)$. Campinas, São Paulo State, Brazil, 2011.

\begin{tabular}{|c|c|c|c|c|}
\hline & Range & n (\%) & Mean (SD) & Median (IQR) \\
\hline \multicolumn{5}{|l|}{ Physical activity measures } \\
\hline \multicolumn{5}{|l|}{ GSLTPAQ (higher score means higher leisure-time physical activity) } \\
\hline Mild activities & $0.0-21.0$ & & $1.0(1.8)$ & $0.0(2.0)$ \\
\hline Moderate activities & $0.0-35.0$ & & $0.4(1.2)$ & $0.0(0.0)$ \\
\hline Strenuous activities & $0.0-45.0$ & & $0.1(0.5)$ & $0.0(0.0)$ \\
\hline \multicolumn{5}{|l|}{ Continuous score } \\
\hline With mild activities & $0.0-60.0$ & & $5.8(9.3)$ & $0.0(9.0)$ \\
\hline Excluding mild activities & $0.0-45.0$ & & $2.8(7.6)$ & $0.0(0.0)$ \\
\hline \multicolumn{5}{|l|}{ Categorized score } \\
\hline Insufficiently active (< 14 units) & & $189(80.1)$ & & \\
\hline Moderately active ( $\geq 14$ and $<23$ units) & & $33(14.0)$ & & \\
\hline Active ( $\geq 24$ units) & & $14(5.9)$ & & \\
\hline \multicolumn{5}{|l|}{ Baecke-HPA } \\
\hline Occupational physical activity (1-5; higher score = higher occupational physical activity) & $1.1-4.7$ & & $2.6(0.9)$ & $2.6(1.9)$ \\
\hline Physical exercise in leisure (1-5; higher score $=$ higher physical exercise in leisure) & $1.0-4.2$ & & $2.1(0.6)$ & $2.0(0.7)$ \\
\hline $\begin{array}{l}\text { Leisure and locomotion activities (1-5; higher score = higher leisure and locomotion } \\
\text { physical activity) }\end{array}$ & $1.0-4.5$ & & $2.5(0.6)$ & $2.5(1.0)$ \\
\hline Total score $(3-15$; higher score $=$ higher total habitual physical activity) & $3.9-12.0$ & & $7.2(1.5)$ & $7.2(2.0)$ \\
\hline \multicolumn{5}{|l|}{ Self-report behavior measure $(1-4$; higher score $=$ higher physical activity $)$} \\
\hline Score & $1-4$ & & $1.7(1.2)$ & $1.0(1.0)$ \\
\hline Less than once a week (1) & & $173(73.3)$ & & \\
\hline Once a week (2) & & $9(3.8)$ & & \\
\hline Twice a week (3) & & $12(5.1)$ & & \\
\hline 3 or more times/week (4) & & $42(17.8)$ & & \\
\hline \multicolumn{5}{|l|}{ Cardiorespiratory fitness measures } \\
\hline \multicolumn{5}{|l|}{ Direct } \\
\hline $\mathrm{VO}_{2 \text { peak }}\left(\mathrm{ml} \cdot \mathrm{kg}^{-1} \cdot \mathrm{min}^{-1}\right)$ & $8.2-42.4$ & & $19.7(5.7)$ & $19.2(6.9)$ \\
\hline \multicolumn{5}{|l|}{ Indirect } \\
\hline VSAQ * $\left(\mathrm{ml}^{\mathrm{kg}}{ }^{-1} \cdot \mathrm{min}^{-1}\right)$ & $5.2-50.7$ & & $22.0(9.8)$ & $20.3(15.0)$ \\
\hline $\mathrm{VO}_{2 \text { pred }}\left(\mathrm{ml} \cdot \mathrm{kg}^{-1} \cdot \mathrm{min}^{-1}\right)$ & $3.5-59.4$ & & $29.1(11.3)$ & $27.2(17.5)$ \\
\hline
\end{tabular}

Baecke-HPA: Baecke Habitual Physical Activity; GSLTPAQ: Godin-Shephard Leisure-Time Physical Activity Questionnaire; IQR: interquartile range; SD: standard deviation; VSAQ: Veterans Specific Activity Questionnaire.

* The original unit of the questionnaire (METs) was converted to $\mathrm{ml}^{.} \mathrm{kg}^{-1}$. $\mathrm{min}^{-1}$, by multiplying the VSAQ score by 3.5 , in order to standardize data, according to the other measures of cardiorespiratory fitness.

\section{Convergent validity of GSLTPAQ}

The analyses revealed significant positive correlations between the GSLTPAQ total score including mild activities and the sub scores of the Baecke-HPA: correlation with PEL score $(r=0.62$; $\mathrm{p}<0.0001)$; with the total score of HPA $(\mathrm{r}=0.36$; $\mathrm{p}<0.0001)$ and with the LLA score $(\mathrm{r}=0.16 ; \mathrm{p}=$ 0.01). The GSLTPAQ total score including mild activities was also significantly correlated with the self-reported measure of walking behavior $(\mathrm{r}=0.62 ; \mathrm{p}<0.0001)$. The GSLTPAQ total score excluding mild activities was significantly associated with the PEL score of the Baecke-HPA ( $\mathrm{r}=$ $0.47 ; \mathrm{p}<0.0001)$, the LLA score $(\mathrm{r}=0.17 ; \mathrm{p}=0.01)$, and the total HPA score $(r=0.25 ; p=0.0001)$ of the Baecke-HPA. The GSLTPAQ excluding mild activity score was also significantly correlated with the self-report measure of walking behavior $(r=0.19$; $\mathrm{p}=0.004$ ) (Table 3).

Significant positive correlations were observed between the GSLTPAQ score including 
Table 3

Partial correlation with 95\% confidence interval (95\% CI) between the GSLTPAQ, Baecke-HPA and the self-report measure of behavior (walking) for the total sample $(\mathrm{N}=236)$. Campinas, São Paulo State, Brazil, 2011.

\begin{tabular}{|c|c|c|}
\hline \multirow[t]{3}{*}{ Physical activity measures } & \multicolumn{2}{|c|}{ GSLTPAQ } \\
\hline & Score including mild activities & Score excluding mild activities \\
\hline & $r^{*}[95 \% \mathrm{Cl}]$ & $r^{*}[95 \% \mathrm{Cl}]$ \\
\hline \multicolumn{3}{|l|}{ Baecke-HPA } \\
\hline Occupational physical activity & $0.02[-0.11,0.15]$ & $0.08[-0.05,0.21]$ \\
\hline Physical exercise in leisure & $0.62 * *[0.53,0.69]$ & $0.47^{\star *}[0.36,0.56]$ \\
\hline Leisure and locomotion activities & $0.16^{\star \star \star}[0.03,0.28]$ & $0.17^{\star \star \star}[0.04,0.29]$ \\
\hline Total score & $0.36^{\star *}[0.24,0.47]$ & $0.25 * \star[0.13,0.37]$ \\
\hline Self-report measure of walking behavior & $0.62 * \star[0.53,0.69]$ & $0.19 \#[0.06,0.31]$ \\
\hline \multicolumn{3}{|c|}{ Baecke-HPA: Baecke Habitual Physical Activity; GSLTPAQ: Godin-Shephard Leisure-Time Physical Activity Questionnaire. } \\
\hline \multicolumn{3}{|c|}{ * Adjusted correlation controlling for sex, age, body mass index, education levels and groups (coronary heart disease and hypertension); } \\
\hline \multicolumn{3}{|c|}{$\star * p<0.001$} \\
\hline \multicolumn{3}{|l|}{$\star * \star p<0.05$} \\
\hline$\# p<0.01$ & & \\
\hline
\end{tabular}

mild activities and $\mathrm{VO}_{2 \text { pred }}(\mathrm{r}=0.15 ; \mathrm{p}=0.03)$ and VSAQ ( $\mathrm{r}=0.23 ; \mathrm{p}=0.0006)$, and between the GSLTPAQ score excluding the mild activities and the $\mathrm{VO}_{2 \text { pred }}(\mathrm{r}=0.19 ; \mathrm{p}=0.004)$. Significant correlation was also observed between the GSLTPAQ score excluding mild activities and the VSAQ $(\mathrm{r}=0.34 ; \mathrm{p}<0.0001)$. No significant correlation was observed between any of the GSLTPAQ total scores and the direct measure of oxygen uptake $\left(\mathrm{VO}_{2 \text { peak }}\right)$ (Table 4$)$.

\section{Divergent validity of GSLTPAQ}

No significant correlation between the GSLTPAQ score and the occupational score of the BaeckeHPA was observed (Table 3). The correlation between the GSLTPAQ score including $(\mathrm{r}=0.02 ; \mathrm{p}=$ $0.73)$ and excluding $(r=0.08 ; \mathrm{p}=0.24)$ mild activities was not significant.

\section{Discussion}

The purpose of this study was to evaluate the measurable properties of the Brazilian version of the GSLTPAQ regarding the aspects of convergent and divergent construct validity.

The unidimensional 1-item questionnaire has presented acceptable levels of convergent validity in order to measure leisure-time physical activity, since significant correlations with both the Baecke-HPA and the self-report measure of behavior were observed. There was a significant correlation between the GSLTPAQ and the PEL sub score, which is a specific domain, related to leisure-time physical activity. In fact, this relation was confirmed when mild activities were both included and excluded. It is also relevant to highlight the divergent validity aspect observed, since no significant correlation was observed between the GSLTPAQ score and the OPA score, from the Baecke-HPA.This finding, in conjunction with the large correlation observed between the GSLTPAQ scores and the specific domain for leisure exercise of the Baecke-HPA, reinforces the capacity of the questionnaire to correctly measure the specific domain of leisure-time physical activity.

Although the correlation coefficient values found were not of a large magnitude, it is well recognized in the international literature that the main finding in studies like this one is to find a significant correlation between objective measures and questionnaires, given the major subjective aspects that permeate the use of psychometric measures 19,34,35, such as the GSLTPAQ. It is therefore safe to report that in our study, the convergent and divergent validity hypotheses were supported by the findings, despite the size of the correlations, since there were significant correlations found between the GSLTPAQ and the direct gold-standard measures, such as peak oxygen.

Regarding the other measure of physical activity used to evaluate convergent validity, the GSLTPAQ score with mild activities presented a large significant coefficient with the self-report measure of walking behavior, but not when these activities were excluded. This was foreseen, since 
Partial correlation and 95\% confidence interval $(95 \% \mathrm{Cl})$ between the GSLTPAQ and VO2peak, VSAQ and VO2pred for the total sample (N = 231). Campinas, São Paulo State, Brazil, 2011.

\begin{tabular}{|c|c|c|}
\hline \multirow[t]{3}{*}{ Cardiorespiratory fitness } & \multicolumn{2}{|c|}{ GSLTPAQ } \\
\hline & Score including mild activities & Score excluding mild activities \\
\hline & $r *[95 \% \mathrm{Cl}]$ & $r *[95 \% \mathrm{Cl}]$ \\
\hline \multicolumn{3}{|l|}{ Direct measure } \\
\hline $\mathrm{VO}_{2 \text { peak }}$ & $0.09[-0.04,0.22]$ & $0.03[-0.10,0.16]$ \\
\hline \multicolumn{3}{|l|}{ Indirect measures } \\
\hline $\mathrm{VO}_{2 \text { pred }}$ & $0.15 * \star[0.02,0.27]$ & 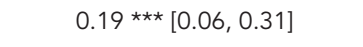 \\
\hline VSAQ & $0.23 \#[0.10,0.35]$ & $0.34 \#[0.22,0.45]$ \\
\hline
\end{tabular}

GSLTPAQ: Godin-Shephard Leisure-Time Physical Activity Questionnaire; VSAQ: Veterans Specific Activity Questionnaire.

*Adjusted correlation controlling for sex, age, body mass index, education and groups (coronary heart disease and hypertension);

** $\mathrm{p}<0.05$

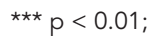

$\# p<0.001$.

the behavior questionnaire is focused on walking behavior only, which is considered a mild physical activity.

Relevant reviews 20,34 highlight that in general the sample population selected for a validation study should reflect the population to whom the questionnaire will be applied. In this subject, physical activity questionnaires are frequently planned to measure populationlevel associations with chronic diseases, such as CHD, hypertension or diabetes; and are commonly tested only among these specific populations. The present study has an advantage in this matter hence GSLTPAQ was tested among a diverse population including not only healthy individuals but also hypertensive and CHD outpatients. Therefore, this sample is representative of the population to which the questionnaire can be applied.

Additionally, participants with BMI $>30 \mathrm{~kg} /$ $\mathrm{m}^{2}$ were excluded in previous physical activitybased studies, since these individuals may be less active 36 . Nevertheless, in this study, it was chosen to include obese individuals, since they represent an important population 37 , even though they may report physical activity differently to the actual pattern 38 .

With regard to recommendations for engaging physical activity practice and considering the lack of international consensus, the most widely accepted guidelines are those sanctioned by the ACSM and the AHA. These associations propose that individuals aged between 18 and 65 should practice a minimum of 30 minutes of moderate physical activity at least 5 days a week, or $20 \mathrm{~min}$ - utes of vigorous physical activity at least 3 days a week, or a combination of the two 39 .

In contrast to this concept, physical inactivity has been defined as less than 150 minutes/ week of moderate physical activity or $60 \mathrm{~min}$ utes/week of vigorous physical activity 25 . In our study, the majority of the sample $(80.1 \%$, $\mathrm{n}=189$ ) was considered insufficiently active according to the GSLTPAQ categorization. Indeed, a large portion of our sample presented a GSLTPAQ score of 0 (zero). Another Brazilian study evaluating the prevalence of leisuretime physical inactivity found that $96.7 \%$ of the sample was inactive considering this domain of physical activity 40 .

The correlation of the GSLTPAQ was also analyzed considering different measures of cardiorespiratory fitness, including the gold standard measure, which is peak oxygen. Although measures of cardiorespiratory fitness are not the gold standard to evaluate physical activity behavior, and considering that no gold standard for physical activity measure has ever been determined, it is expected that more active people will develop a better level of physical fitness than those with lower levels of physical activity, or those who are inactive 16 . This justifies the use of peak oxygen as the criterion for evaluating convergent validity in this study. Thus, the correlations observed between the GSLTPAQ scores and auto-reported (VSAQ) and predicted values $\left(\mathrm{VO}_{2 \text { pred }}\right)$ of cardiorespiratory fitness were expected and proven in this study, as evidenced by others that tested this assumption 6,41 . It is worthwhile to emphasize that the correlations observed between the 
GSLTPAQ and the indirect measures of cardiorespiratory fitness were higher when the mild activities are excluded from the score, which reinforces previous findings stating that cardiorespiratory fitness measures are better correlated with strenuous activities 6,41.

However, correlations were not observed between the GSLTPAQ scores and the direct measure of cardiorespiratory fitness $\left(\mathrm{VO}_{2 \text { peak }}\right)$. There are some possible explanations as to why leisure-time physical activity outcomes did not directly reproduce cardiorespiratory fitness: among CHD and hypertensive outpatients, the patients' condition noticeably limits the range of activities that they are able to perform, as reported elsewhere 42 . In this study, this absence of correlation may be explained first by the factor of the submaximal nature of the cardiopulmonary exercise test performed. It is not possible to assure that participants of this study reached the $\mathrm{VO}_{2 \max }$ due to their health status, thus the $\mathrm{VO}_{2 \text { peak }}$ should be considered for the analyses, as recommended 35 . The use of $\mathrm{VO}_{2 \text { peak }}$ to represent $\mathrm{VO}_{2 \max }$ has some limitations, since the accuracy of this estimation may be affected by the presence and extent of disease, among other factors 35 . Further studies involving cardiorespiratory fitness assessment by direct measures should consider the anaerobic threshold as a valid measure, since this parameter allows for the evaluation of aerobic performance at submaximal powers 43 .

Second, the very sedentary pattern of the studied population, evidenced by the narrow variation of the GSLTPAQ scores and the concentration in the inactive category also helps to explain this finding. Other studies which tried to assess the relationship between direct measures of oxygen uptake and physical activity questionnaires were also not successful at obtaining significant correlations, as described in Japan 44 and the United States 41.

It is important to highlight that the interviewadministered version of the Brazilian GSLTPAQ was tested, thus the evidence of validity relates to this mode of administration of the questionnaire. Further studies may be necessary in order to evaluate the validity of the Brazilian version of the GSLTPAQ when self-administered. Therefore, this may be a limit to the generalization of the results regarding external validity.

According to the Qualitative Attributes and Measurement Properties of Physical Activity Questionnaires study (the QAPAP) ${ }^{19}$, the highest level of evidence for validity would be obtained by comparing the physical activity questionnaire with a gold standard, i.e., the instrument that measures the same construct and has perfect reliability and validity (also known as criterion valid- ity). In this sense, the more similar the constructs that are being compared, the more evidence is provided. Therefore, comparison with objective measures of physical activity is considered the best level of evidence (1 or 2) and constructs not really measuring current physical activity (such as maximal oxygen uptake) or another questionnaire, provide a level 3 of evidence 20 , as observed in the present study.

Finally, in evaluating the validity of the GSLTPAQ as a measure of general physical activity behavior, positive evidence of its validity must be considered; from the significant correlations observed with all the other measures of physical activity (questionnaires) and the predicted measures of cardiorespiratory fitness, despite the low variability in the GSLTPAQ score. Another main strength of the present study consists of its sample size being relatively large for validation studies, especially those using direct measures such as gas analyses. Nevertheless, the major strength of the study is to present evidence of two types of validity - convergent and divergent, among a large sample including a diverse population that cover cardiovascular disease outpatients, since it is not usual to evaluate them as presented in this paper, with direct measures of physical fitness such as direct $\mathrm{VO}_{2 \text { peak }}$.

\section{Limitations of the study}

As with other validation studies which include both direct and indirect measures of physical activity, this study is not without its limitations since pedometers were not used, although walking is the most practiced physical activity in Brazil. Their use was not possible since individuals had only one meeting with the researcher, since the setting was an outpatient clinic which they did not attend regularly. This particularity could be harmful to the data collection procedure, since the pedometers would have to be returned to the researcher. It is also worth mentioning that such devices tend to underestimate walking and overestimate jogging activity, and may also show only weak relations to maximal oxygen intake 34 . The fact that more than $80 \%$ of the sample was considered inactive according to the GSLTPAQ score was also a limitation, since the score variation was limited and recommended the use of the dichotomized score instead of the continuous score. In further studies using the Brazilian GSLTPAQ, we recommend that the responsible statistician evaluate if there is a need of dichotomizing the data, according to its variability. The heterogeneous aspect of the Brazilian population should also be considered, especially because it 
is a populous country, characterized by a large number of states with different cultural aspects. In this sense, the administration of the questionnaire in different regions of the country is recommended, in addition to the southeast, among individuals with different sociodemographic and clinical characteristics.

\section{Conclusion}

The Brazilian version of the GSLTPAQ demonstrated level 3 of evidence of validity with indirect measures of physical activity and cardiorespiratory fitness, suggesting that this questionnaire is a valid tool to estimate physical activity in leisure-time in the Brazilian population with or without cardiovascular disease. Further studies are recommended in order to corroborate or add to this level of evidence.

\section{Resumen}

Este estudio proporciona evidencia de validez de constructo de la versión brasileña del Godin-Shephard Leisure-Time Physical Activity Questionnaire (GSLTPAQ), instrumento de 1 item utilizado entre 236 participantes referidos a la prueba de esfuerzo cardiopulmonar. El Cuestionario de Actividad Física Habitual de Baecke (AFH-Baecke) se utilizó para evaluar la validez convergente y divergente. La medida de autoreporte de caminar (QCAF) evaluó la validez convergente. Aptitud cardiorrespiratoria fue evaluada por el Veterans Specific Activity Questionnaire (VSAQ), medida pico $\left(V O_{2 \text { pico }}\right)$ y máximo $\left(V O_{2 p r e d}\right)$ del consumo de oxígeno. Coeficientes de correlación parciales ajustados entre el GSLTPAQ, AFH-Baecke, QCAF, VO ${ }_{2 \text { pred }} y$ VSAQ investigaran la validez convergente; $y$ la validez divergente fue apoyada por ausencia de correlación entre GSLTPAQ y la Actividad Física Ocupacional (AFHBaecke). El GSLTPAQ presenta nivel 3 de evidencia de validez de constructo y puede ser útil para valorar la actividad física en el tiempo libre entre los pacientes con enfermedad cardiovascular y individuos sanos.

Enfermedades Cardiovasculares; Actividad Motora; Estudios de Validación; Cuestionarios; Psicometría 


\section{Contributors}

T. M. São João made substantial contributions to the conception and design of the work, and to the acquisition, analysis, and interpretation of data for the work; drafting the work and revising it critically for important intellectual content; approved the final version of the paper. R. C. M. Rodrigues made substantial contributions to the conception and design of the work, and approved the final version of the paper. M. C. B. J. Gallani drafting the work and revising it critically for important intellectual content, and approved the final version of the paper. C. T. P. Miura and G. B. L. Domingues contributed to the acquisition, analysis, and interpretation of data for the work, and approved the final version of the paper. S. Amireault contributed to the analysis and interpretation of data for the work; critically revising for important intellectual content; and approved the final version of the paper. G. Godin revising the work critically for important intellectual content, and approved the final version of the paper.

\section{References}

1. American Heart Association. Heart disease and stroke statistics - 2012 update: a report from the American Heart Association. Circulation 2012; 125:e2-e220.

2. Caspersen CJ, Powell KE, Christenson GM. Physical activity, exercise, and physical fitness: definitions and distinctions for health-related research. Public Health Rep 1985; 100:126-31.

3. Brown H, Roberts J. Exercising choice: the economic determinants of physical activity behaviour of an employed population. Soc Sci Med 2011; 73:383-90.

\section{Acknowledgments}

We thank Dr. Marcelo Ramos (AME-Limeira) and Professor Neusa M. C. Alexandre (Fenf-Unicamp). This work was supported by the National Council for Technological and Scientific Development (grant $\mathrm{n}$. 142392/2009-0, 200458/2011-6 and 555355/2009-8) and by the State of São Paulo Research Foundation (grant $\mathrm{n}$. 2010/10006-8).

\section{Declaration of conflicting interests}

The authors declare that there is no conflict of interest.
4. Church TS, Thomas DM, Tudor-Locke C, Katzmarzyk PT, Earnest CP, Rodarte RQ, et al. Trends over 5 decades in U.S. occupation-related physical activity and their associations with obesity. PLoS One 2011; 6:e19657.

5. Seiluri T, Lahti J, Rahkonen O, Lahelma E, Lallukka T. Changes in occupational class differences in leisure-time physical activity: a follow-up study. Int J Behav Nutr Phys Act 2011; 8:14. 
6. Caspersen CJ, Merrit RK, Stephens T. International physical activity patterns: a methodological pespective. In: Dishman RK, editor. Advances in exercise adherence. Champaign: Human Kinetics Books; 1995. p. 73-110.

7. Godin G, Shephard RJ. A simple method to assess exercise behavior in the community. Can J Appl Sport Sci 1985; 10:141-6.

8. Ainsworth BE, Berry CB, Schnyder VN, Vickers SR. Leisure-time physical activity and aerobic fitness in African-American young adults. J Adolesc Health 1992; 13:606-11.

9. Noreau N, Shephard RJ, Simard C, Paré G, Pomerleau P. Relationship of impairment and functional ability to habitual activity and fitness following spinal cord injury. Int J Rehab Res 1993; 16:265-75.

10. Sallis JF, Buono MJ, Roby JJ, Micale FG, Nelson JA. Seven-day recall and other physical activity self-reports in children and adolescents. Med Sci Sports Exerc1993; 25:99-108.

11. Miller DJ, Freedson PS, Kline GM. Comparison of activity levels using the Caltrac ${ }^{\circledR}$ accelerometer and five questionnaires. Med Sci Sports Exerc 1994; 26:376-82.

12. Smith SS, Doyle G, Pascoe T, Douglas JA, Jorgensen G. Intention to exercise in patients with obstructive sleep apnea. J Clin Sleep Med 2007; 3:689-94

13. Valenti M, Porzio G, Aielli F, Verna L, Cannita K, Manno R, et al. Physical exercise and quality of life in breast cancer survivors. Int J Med Sci 2008; 5:24-8.

14. Stephenson LE, Bebb DG, Raylene A, Reimer RA, Culos-Reed SN. Physical activity and diet behaviour in colorectal cancer patients receiving chemotherapy: associations with quality of life. BMC Gastroenterol 2009; 9:60.

15. Motl RW, Goldman M. Physical inactivity, neurological disability, and cardiorespiratory fitness in multiple sclerosis. Acta Neurol Scand 2011; 123:98-104.

16. Jacobs DR, Aisworth BE, Hartman TJ, Leon AS. A simultaneous evaluation of 10 commonly used physical activity questionnaires. Med Sci Sports Exerc 1993; 25:81-91.

17. American College of Sports Medicine. Godin Leisure-Time Exercise Questionnaire. Med Sci Sports Exerc 1997; 26:S36-8.

18. Godin G. The Godin-Shephard Leisure-Time Exercise Questionnaire. The Health \& Fitness Journal of Canada 2011; 4:18-22.

19. Terwee CB, Mokkink LB, van Poppel MNM, Chinapaw MJM, van Mechelen W, de Vet HCW. Qualitative attributes and measurement properties of physical activity questionnaires: a checklist. Sports Med 2010; 40:525-37.

20. van Poppel MNM, Chinapaw MJM, Mokkink LB, van Mechelen W, Terwee CB. Physical activity questionnaires for adults: a systematic review of measurement properties. Sports Med 2010; 40:565-600.

21. São-João TM, Rodrigues RCM, Gallani MCBJ, Miura CT, Domingues GB, Godin G. Cultural adaptation of the Brazilian version of the Godin-Shephard Leisure-Time Physical Activity Questionnaire. Rev Saúde Pública 2013; 47:1-8.
22. Mendez RDR, Rodrigues RCM, Cornélio ME, Gallani MCBJ, Godin G. Development of an instrument to measure psychosocial determinants of physical activity behavior among coronary heart disease patients. Rev Esc Enferm USP 2010; 44:583-94.

23. Ramalho JR, Lima-Costa MF, Firmo JO, Peixoto SV. Energy expenditure through physical activity in a population of community-dwelling Brazilian elderly: cross-sectional evidences from the Bambuí Cohort Study of Aging. Cad Saúde Pública 2011; 27 Suppl 3:S399-408.

24. Florindo AA, Latorre MRDO, Jaime PC, Tanaka T, Zerbini CAF. Methodology to evaluation the habitual physical activity in men aged 50 years or more. Rev Saúde Pública 2004; 38:307-14.

25. Hallal PC, Matsudo SM, Matsudo VKR, Araújo TL, Andrade DR, Bertoldi AD. Physical activity in adults from two Brazilian areas: similarities and differences. Cad Saúde Pública 2005; 21:573-80.

26. Florindo AA, Latorre MRDO, Santos ECM, Negrão CE, Azevedo LF, Segurado AAC. Validity and reliability of the Baecke questionnaire for the evaluation of habitual physical activity among people living with HIV/AIDS. Cad Saúde Pública 2006; 22:535-41.

27. Domingues GBL, Gallani MCBJ, Gobatto CA, Miura CTP, Rodrigues RCM, Myers J. Cultural adaptation of an instrument to assess physical fitness in cardiac patients. Rev Saúde Pública 2011; 45: 276-85.

28. Myers J, Do D, Herbert W, Ribisl P, Froelicher VF. A nomogram to predict exercise capacity from a specific activity questionnaire and clinical data. Am J Cardiol 1994; 73:591-6.

29. Myers J, Buchanan N, Smith D, Neutel J, Bowes $\mathrm{E}$, Walsh D, et al. Individualized ramp treadmill. Observations on a new protocol. Chest 1992; 101:236S-41S

30. Meneghelo RS, Araújo CGS, Stein R, Mastrocolla LE, Albuquerque PF, Serra SM, et al. III guidelines of the Brazilian Society of Cardiology about the cardiopulmonary test. Arq Bras Cardiol 2010; 95:1-26.

31. Bassett Jr. DR, Howley ET. Limiting factors for maximum oxygen uptake and determinants of endurance performance. Med Sci Sports Exerc 2000; 32:70-84.

32. Polit DF, Beck CT. Fundamentos de pesquisa em enfermagem. 7a Ed. Porto Alegre: Editora Artes Médicas; 2011.

33. McDowell I, Newell C. Measuring health: a guide to rating scales and questionnaires. 2nd Ed. New York: Oxford University Press; 1996.

34. Shephard RJ. Limits to the measurement of habitual physical activity by questionnaires. Br J Sports Med 2003; 37:197-206.

35. Arena R, Myers J, Williams MA, Gulati M, Kligfield P, Balady GJ, et al. Assessment of functional capacity in clinical and research settings: a scientific statement from the American Heart Association Committee on Exercise, Rehabilitation, and Prevention of the Council on Clinical Cardiology and the Council on Cardiovascular Nursing. Circulation 2007; 116:329-43. 
36. Elosua R, Marmgat J, Molina L, Pons S, Pujol E. Validation of the Minnesota Leisure Time Physical Activity Questionnaire in Spanish men. Am J Epidemiol 1994; 139:1197-209.

37. Freedman DS; Centers for Disease Control and Prevention. Obesity - United States, 1988-2008. MMWR Surveill Summ 2011; 60 Suppl:73-7.

38. Watkinson C, van Sluijs EM, Sutton S, Hardeman W, Corder K, Griffin SJ. Overestimation of physical activity level is associated with lower BMI: a cross-sectional analysis. Int J Behav Nutr Phys Act 2010; 7:68.

39. Haskell WL, Lee IM, Pate RR, Powell KE, Blair SN, Franklin BA, et al. Physical activity and public health: updated recommendation for adults from the American College of Sports Medicine and the American Heart Association. Circulation 2007; 39:1423-34.

40. Monteiro CA, Conde WL, Matsudo SM, Bonsenor IM, Lotufo PA. A descriptive epidemiology of leisure-time physical activity in Brazil, 1996-1997. Rev Panam Salud Pública 2003; 14:246-54.
41. Blair SN, Haskell WL, Ho P, Paffenbarger RS, Vranizan KM, Farquhar JW, et al. Assessment of habitual physical activity by a sevenday recall in a community survey and controlled experiments. Am J Epidemiol 1985; 122:794-804.

42. Myers J, Gullestad L, Bellin D, Ross H, Vagelos R, Fowler M. Physical activity patterns and exercise performance in cardiac transplant recipients. J Cardiopulm Rehabil 2003; 23:100-6.

43. Gallo Jr. L, Maciel BC, Marin-Neto JA, Martins LE, Lima-Filho EC, Golfetti R, et al. Control of heart rate during exercise in health and disease. Braz J Med Biol Res 1995; 28:1179-84.

44. Ishikawa-Takata K, Naito Y, Tanaka S, Ebine N, Tabata I. Use of doubly labeled water to validate a physical activity questionnaire developed for the Japanese population. J Epidemiol 2011; 21:114-21.

Submitted on $05 /$ Nov/2013

Final version resubmitted on 18/Jun/2015

Approved on 06/Jul/2015 